\title{
Research on Smart Development in Urban Central Axis Area Based on Morphological Typology Method and Environmental Synergy Concept \\ -- A Case Study of TIT Creative Park in Guangzhou
}

\author{
Minzhi $\mathrm{Li}^{1, \mathrm{a}}$, Lu Wang ${ }^{2, \mathrm{~b}}$ \\ ${ }^{1}$ School of Architecture, South China University of Technology, Guangzhou, China, 510640 \\ ${ }^{2}$ School of Architecture, South China University of Technology, Guangzhou, China, 510640 \\ aliisthebest@126.com, ${ }^{b}$ archwl@126.com
}

\begin{abstract}
Key words: T.I.T Creative Park; Smart Development; Urban Central Axis Area; Morphological Typology Method; Environmental Synergy Concept

Abstract: This research is mainly built upon the work of 2014 Watersheds PhD Winter School, which is organized by South China University of Technology in collaboration with Politecnico di Torino. The Winter School focuses on the professional and practical issues of urban design, specifically, the urban transformation of T.I.T (a former textile factory) and its surroundings which is a very important heritage in Guangzhou and shows the space and scale jumps in time during the rapid developing period. Seven keywords are used to define the research framework: "Simulation", "Methodology", "Divergence/convergence", "Design \& measure", "Formalization", "Circular causation" and "Hybridization". The research combines morphological typology methods and environmental synergy concepts, and incorporates different disciplinary expertise spanning from spatial design (architectural and urban dimensions) to environmental and strategic evaluation. The morphological typology methods make it possible to work on different scales (from small to extra-large dimension) and to consider complex strategies. Environmental synergy concepts are derived from the analysis of the complicated development history and current constructing situation of the urban central axis area where T.I.T is located. Based on the comparison of multiple conflicting actors, values and views of urban regeneration processes and several planning and design scenarios for this area, the research achieves an everlasting urban structure and a growth strategies system with ever-changing surroundings for the Central Axis Area.
\end{abstract}

\section{Introduction}

With the continuous improvement of system integrity and influence of modern urban design, when facing the choice for the future development of the urban essential area, we can analyze the correlation between the complex factors from a more comprehensive perspective in order to provide a more open and adaptive policy framework for scientific decision-making, compare and evaluate the develop scenarios for all kinds of factors in different conditions, scale and environment from a more intuitive spatial morphology perspective, so as to establish a new mechanism of collaborating the history, culture and economy, ecological and aesthetic systems for the new urbanization process. This research is mainly based on the work of 2014 Watersheds PhD Winter School on T.I.T site and the urban transformation of its surroundings which were cooperated between South China University of Technology and Politecnico di Torino on professional and practical issues of urban design. 


\section{Urban Design Research Framework}

There should be a methodological research framework for this urban design program. First, we set up a "Simulation" of the urban regeneration process to establish a possible staged structure for the real values and stakeholders of this area. Second, the "Methodology" has a circular structure: each round of listening and stakeholder analysis supports the urban design of alternative scenarios and the assessment of the qualitative criteria for their subsequent evaluation. Analytic Hierarchy Process and Multi Attribute Value Theory methods were used to help each selection. Third, "Divergence/convergence" always leads to new controversies and incorporates new values that are not considered before. The combination of divergence and convergence is beneficial for legitimizing and refining the set of alternatives. Fourth, the policy is generated through a physical "design \& measure" process, in which we tried to build coherent relationships between the technical aspects of the transformation of space and the political procedures of decision-making. Fifth, we tried to make a progressive "Formalization" to stimulate the phase of political decision comes after the evaluation and the technical assessment of the context in each dimension of complexity. Sixth, the drawing phases are always integrated with the analytical process of measurement. The "Circular causation" process also shows the design scenarios can be measured as far as design actions are tools for measuring. Finally, the "Hybridization" method provides more potential alternatives and possible coexistence of the best options rather than a conventional finalizing solution.

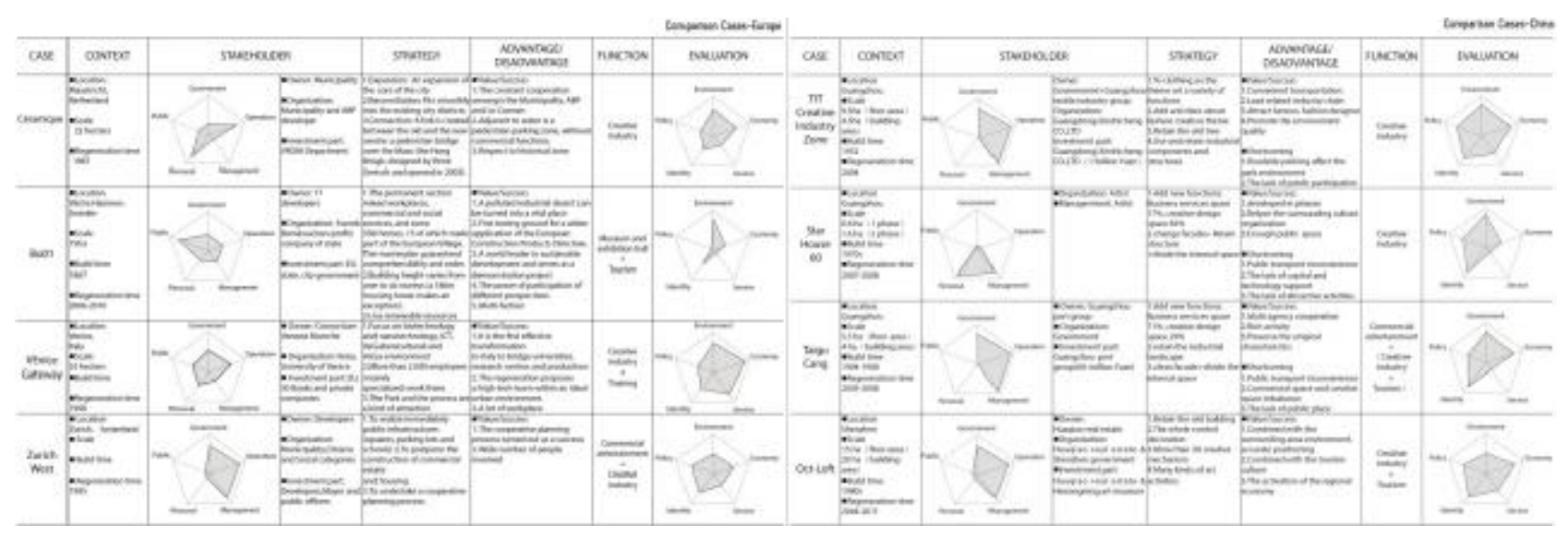

Fig. 1: Comparative Study of Industrial Zone Regeneration Cases

\section{Cases Study}

First of all, we set up a comparison research between Europe and China from the aspects of "Economic environment", "Policy environment", "Result" and "Strategy" of the developed process from 1950's to 2010's. Based on this, an analysis of the "National Economic Reform" system was proposed in order to reveal most of the background elements related to the economic develop phenomenon. Then we chose 7 industrial zone regeneration cases in Europe comparing to 8 cases (especially 3 in Guangzhou) in China for targeted analysis as the Fig. 1 shows (part of whole). The consequence is that the aspects of "Management", "Investment", "Develop model" and "Evaluation rank" are so different between Europe and China. 


\section{T.I.T Creative Park}
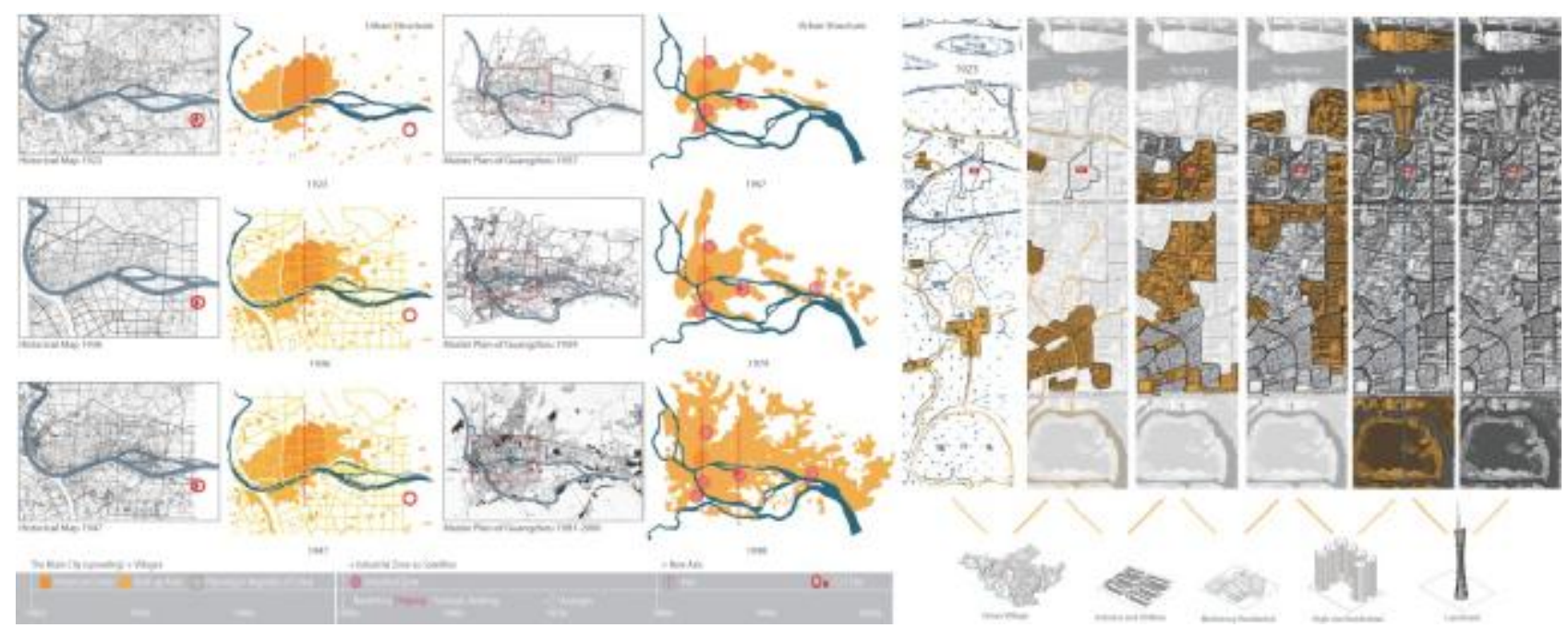

Fig. 2: The history of Guangzhou City \& T.I.T Creative Park Development

The T.I.T industrial zone develop history is a part of the history of Guangzhou then, of China. It requires a new set of urban design tools by thinking about the industrial heritage within on-going urban development processes. Working on different scales, contexts and dimensions is needed to broaden the understanding and refine the instruments of this program. We used a series of historical maps to analyze the development process of the urban central axis area even of the whole city (Fig. 2).

From 1950s to 1970s, Guangzhou city started to change its development from a concentric style to a satellite and isolated style by established several Industrial Zones pointing eastward which included the T.I.T Area. The built-up area expended rapidly towards the East and gradually the new Urban Central Axis Area was constructed. Nowadays, some of the natural or artificial boundaries are still recognizable in the current urban context of this area because of the complicated situations of stakeholders. But after 2000s especially the hold of the 2010 Asian Games, the southern part of the new axis became more and more actively constructed. It's the right time to rethink and make a better choice for the future development of this area. 

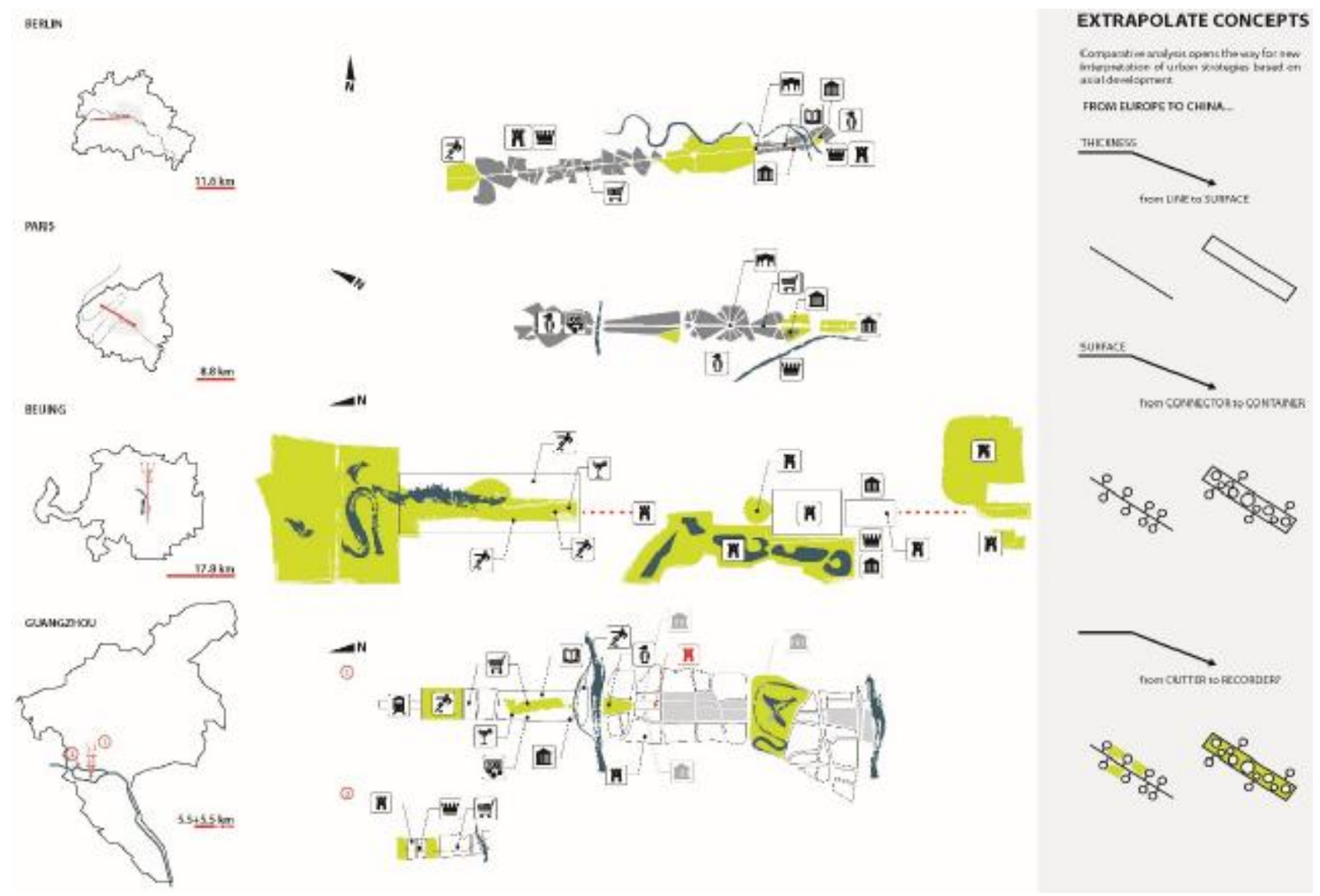

Fig. 3: The comparative analysis of urban axis area development

The comparative analysis of urban axis area development from Europe to China, from the last to this century also opens the way for a new interpretation of urban strategies based on axial development. The cases show the importance of the scale jump as well as highlight all the potentialities for rethinking urban strategies based on conceptual analysis of urban development (Fig. 3). Re-thinking axial strategies from tools for development to tools for preservation. Under this point of view, Guangzhou New Urban Axis becomes a system of urban preservation rather than development at the largest scale. It becomes a recording device able to keep track of the growth of the city in different time and events, and also to accommodate any Form-typology from urban village to corporate towers and international signed buildings, especially the ever-changing surroundings.

\section{Urban Scenarios for T.I.T}

Urban Design can be regarded as a multifaceted concept which includes different perspectives. The process will be characterized by many conflicting values and views, a wealth of possible outcomes and high uncertainty. The evaluation of alternative scenarios is therefore a complex decision problem where different aspects need to be considered simultaneously, the social vision, preference and feelings also need to be considered. This research aims at proposing a multi-methodological approach for supporting strategic planning and design in the domain of urban and territorial projects. Different tools were combined for designing complex urban regeneration processes. From very general transformation scenarios to a more detailed preliminary project, the multi-methodological approach is organized according to subsequent steps, involving the application of different evaluation methods, namely SWOT analysis, stakeholders analysis and Multi-criteria Analysis, taking into account both the methodology of the Analytic Hierarchy Process (AHP) and the Multi Attribute Value Theory (MAVT) . 
In particular, the first phase is related to the structuring of the decision problem in order to define the goal of the project and to identify possible alternative solutions for reaching the goal. It's based on the SWOT analysis and a logical procedure that allows the data and information on a specific decision problem to be collected and organized. The focus is the definition of the possible development scenarios for an area which derive from the valorization of the strengths and the mitigation of the weakness in the light of the opportunities and threats which could occur.

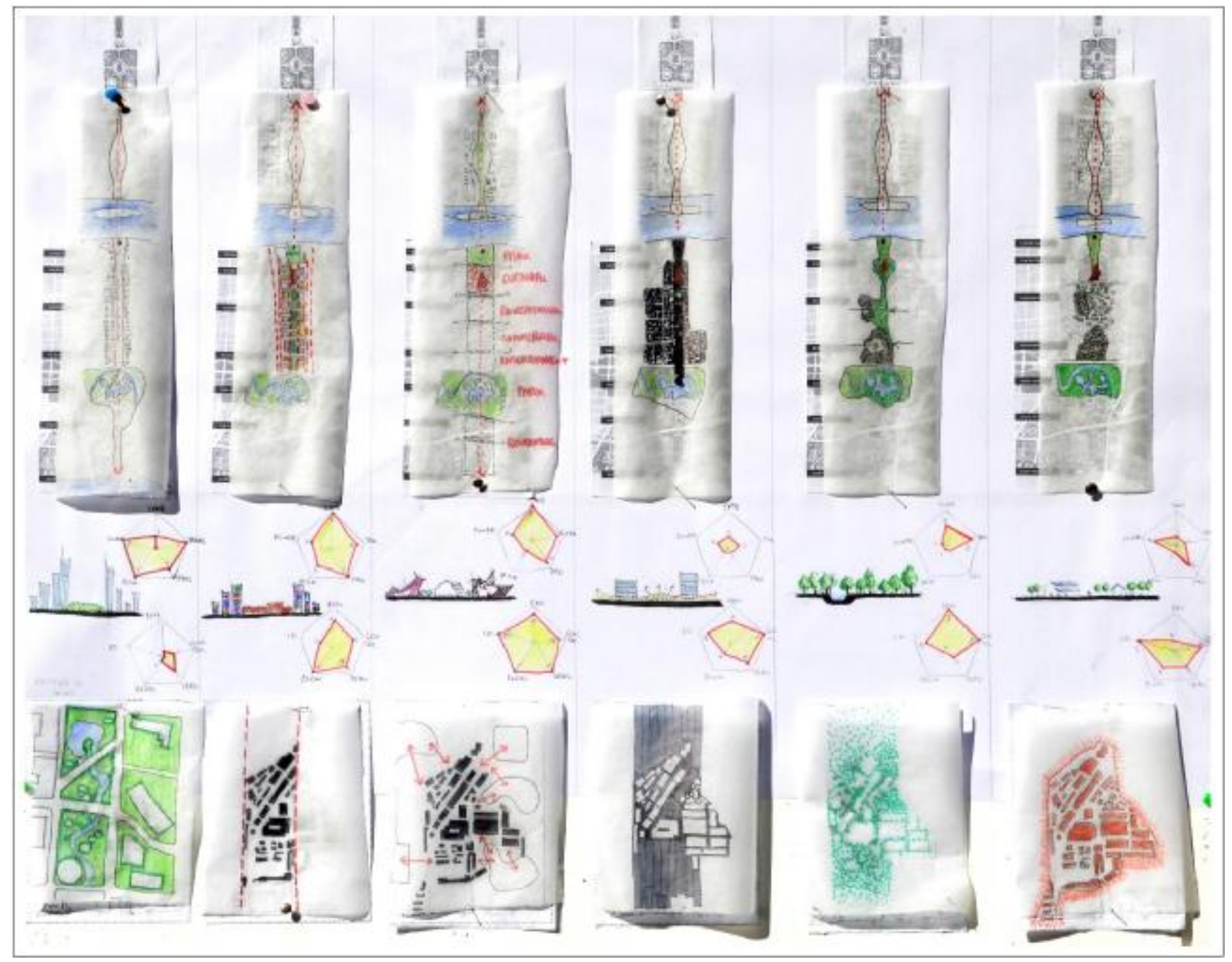

Fig. 5: The Comparative Urban Design Scenarios

The second phase is the development stakeholder analysis aiming at identifying the actors involved in the problem, as well as their values and objectives. The theory is based on the identification and classification of the stakeholder groups, which can be defined as those that who can affect the realization of organizational, goals or group of individuals affected by the realization of organizational goals. A power/interest matrix is constructed in the stakeholders mapping, which allows the comprehension of crucial issues, such as the level of interest of each stakeholder group to impress its expectation on the project decisions and the powerful of each group of affecting the project decisions.

\section{(1). The First Round}

The Axis: The solution retraces the Government Plan for the design of an urban axis to be the continuation of the new northern Axis. The axial distribution of functions along the development that connects the river to the new urban basin lake and again to the river to the south. It offers the possibility to make a new strong mark on the city in its most developing district.

Real Estate Development: This solution attempts to maximize the economical value of the 
development by organizing the urban structure according to a hierarchy of mid- and high-rise. These buildings make the most of their location along an expensive green axis.

Urban Stripes: The most important value in this scenario is the interaction among clusters of clearly defined functions, such as cultural, commercial, entertainment and residential zones. Different zones are divided mainly by transversal mobility, and they are highly permeable. They form a set of well-equipped urban machines, but they are relatively uniform within each "stripe". Around the T.I.T Industrial Park are four museums under construction, therefore it becomes the core of the cultural stripe, an interstitial space connecting these museums as well as a characteristic intro of the whole series of the "urban stripes".

Shared Void: It means the open public place shared with local residents and communities. It preserves and enhances the community value by studying the pre-exist urban textures and the morphology of neighborhoods. Intentions of this scenario are to create opportunities of new daily-life encounters within the public void, and to strengthen the human scale life space in the metropolitan background. The T.I.T Industrial Park can be considered as a community itself, with chances of many events happening both inside and outside.

Green Core: This scenario intended to create a sort of urban forest, in which the environmental effect is considered as most important, not only in the dimension of ecology, but also regarding the essential quality of urban life. Therefore, the prosperous vegetation inside T.I.T is of highly integrated value. Following the green areas under the Guangzhou Tower, patches of small woods cover the land and the visual axis is thus softened, winding its way through this "Forest". This curve-shaped green area extended all way long until it meets the villages. "Forest" turned into aligned trees with full respect of the original borders and forms of these villages.

Heritage: This plan is mainly focused on the conservation of T.I.T area as a memory of previous texture factories. The area will become a sort of fenced enclosure, for example, an open-air museum. All the original urban fabric will be conserved, and interventions will be made only on occasions of necessary adjustment. It could be thought of as an experiment of a totally bottom-up solution to this typology of urban issue, especially in a metropolitan area like Guangzhou, with new possibilities and new patterns of negotiation.

The Multi-Schemed comparison process is useful as a Multi-Criteria Analysis that is valuable and increasing widely-used tool aid decision-making where there is a choice to be made between competing options. AHP method is used to offer a framework to deal with complex decisions which provides a comparison of the different options. It allows tangible and intangible elements to be incorporated simultaneously in the evaluation, through the use of both real data and experts' subjective decisions. A complex problem can be divided into several sub-problems that are organized according to hierarchical levels. It permits factors to be compared with the importance of individual factors being relative to their effects on the problem solution, and the priority list of the considered alternatives to be reached. And after the test process of Sensitivity Analysis on the final outcome of the AHP model, the last three scenarios namely "The Axis", "Urban Stripes" and "Green Core" have been selected to be the most performing options (Fig. 6). 


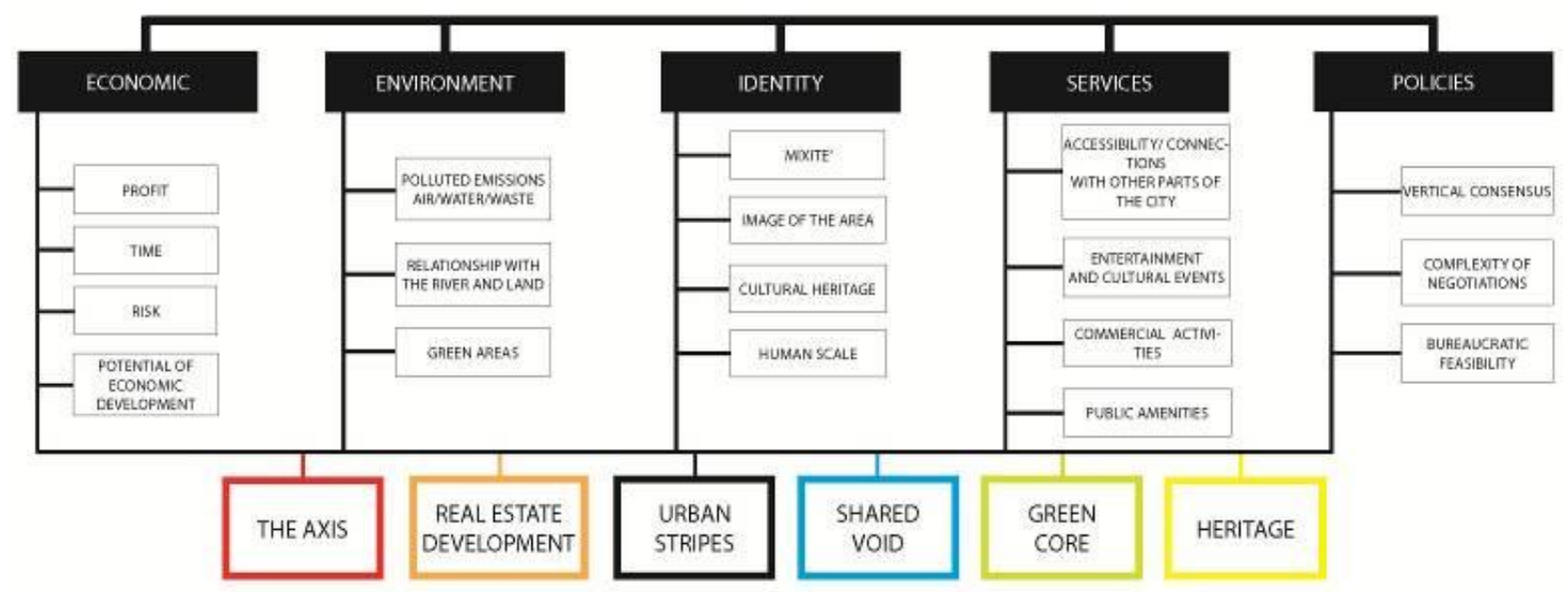

Fig. 6: The Multi-Criteria Analysis \& The Sensitivity Analysis Process

\section{(2). The Second Round}

Re: Green Core II: On the second round, the "Green Core" scenario is again intended to create a sort of urban forest, in which the environmental effect is considered as most important not only in the dimension of ecology but also regarding the essential quality of urban life. Therefore, the prosperous vegetation inside T.I.T is of highly integrated value. A softened and curve-shaped green area extends along the central axis area respecting the original borders and forms of the villages, while high-rise buildings are arranged on the edge of the green area to maintain a certain density as well as a strong transversal permeability.

Re: Urban Stripes II: This scenario's most important value is to be the interaction among cluster of clearly defined functions, such as cultural, commercial, entertainment and residential zones. Together they form a set of well-equipped urban machines. Around the T.I.T Industrial Park are four museums under construction: it becomes the core of the cultural "Stripe", whereas the role of it remains these museums as well as a characteristic intro of the whole series of the "Urban Stripes". Particular attention is devoted to the internal connectivity of the spaces and the variety of urban typologies present.

Re: The Axis II: The second variation of this solution again retraces the Government Plan for the design of an urban axis to be the continuation of the new northern Axis. The proposal stresses the axial distribution of functions along a development that connects the river to the new basin lake and again to the south. The design offers the possibility to make a new strong mark on the city in its most developing district.

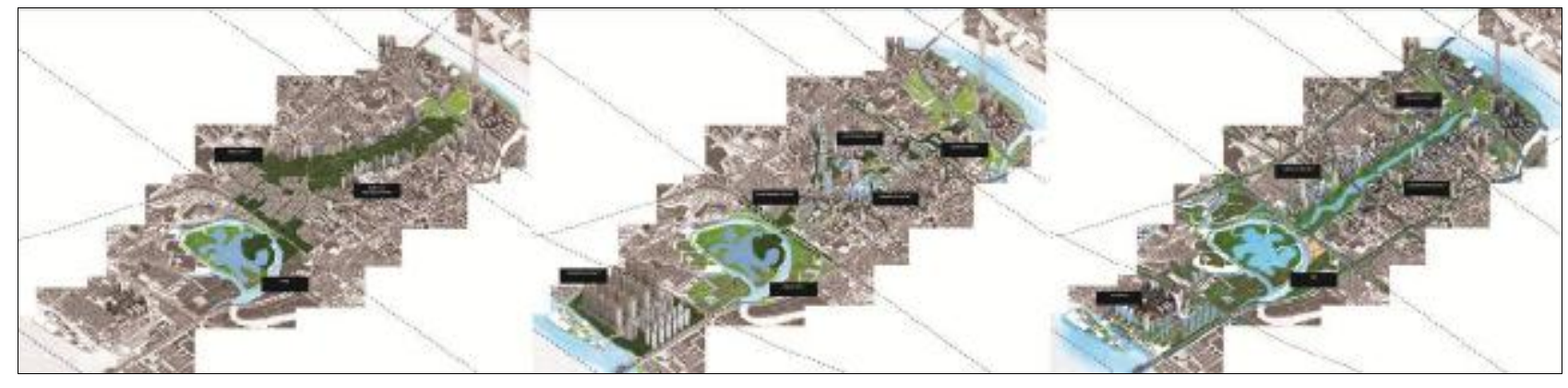

Fig. 7: The three Deduced Urban Design Scenarios in the Second Round 


\section{Conclusions}

This research shows that the MAVT can better differentiate the three scenarios' performance and obtain more stable results. The intention of MAVT is to construct a way to associate a real number with each alternative that is consistent with the Decision Maker value judgments. And the alternative with the best value is then identified as the best. The MAVT model consists of the following five fundamental steps:

(1). Defining and structuring the fundamental objective and related attributes;

(2). Identifying alternative options;

(3). Assessing the scores for each alternative in terms of each criterion;

(4). Modeling preferences and value trade-offs: elicitation of value functions associated with objectives and attributes and assessment of their weights;

(5). Ranking of the alternatives: a total score is calculated for each alternative by applying a value function to all criteria's scores.

The structured iterative process was delineated by a series of tasks, issues and feedback loops that have formed and influenced the design projects during the evaluation.

Finally, the discussion oriented towards values allowed to acquire more insight into the decision, to focus on the key aspects of the problem and to drive the thinking process in an organized way. In fact, conventional approaches for decision-making focus on alternatives. Instead, the method that has been followed in the present study was based on the so-called "values-focused thinking approach" that allows for being pro-active and for the creation of new alternatives and opportunities. 


\section{MOST SUSTAINABLE}

SCENARIO
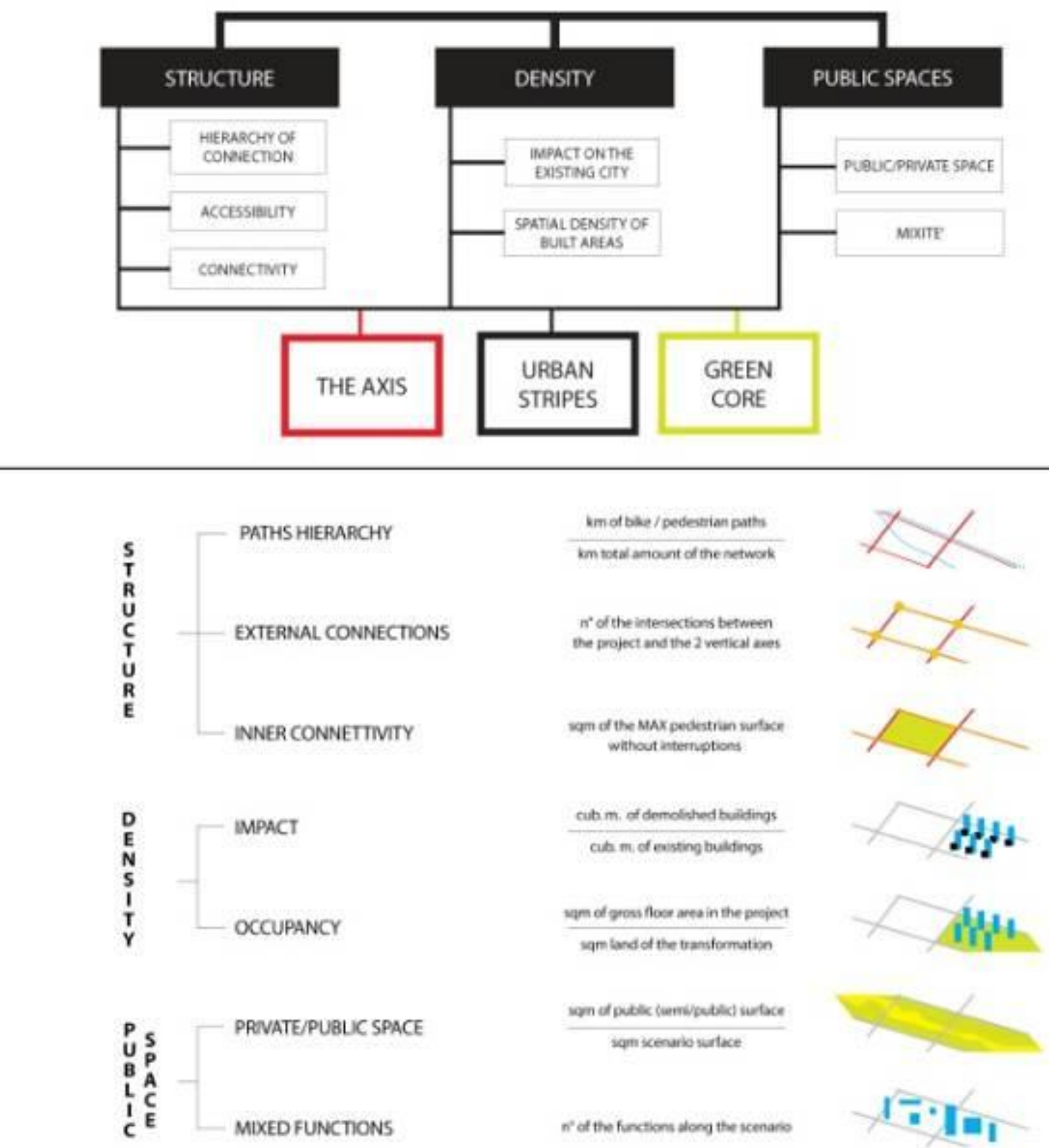

Fig. 8: The MAVT Analysis

The final scenario is an attempt to integrate the strengths of the previous three scenarios into one design, while minimizing their weaknesses. From the Urban Stripes design, the structure of functional clusters is kept and maximized; in particular, the museum district is organized around the T.I.T. area which is kept as intact as possible. From the Green Core scenario, an urban forest runs 
through the site and offers a true lung of vegetation inside the city. From The Axis scenario, the longitudinal axis remains, which connects the river to the lake and then again to the river. Additionally, a transversal connection system allows the site to be extremely permeable to the city on the east and on the west.

Obviously, this is not an in-depth design, but rather a suggestion on how a different decision making process can influence the design of cities. Which is the major contribution of this research program.

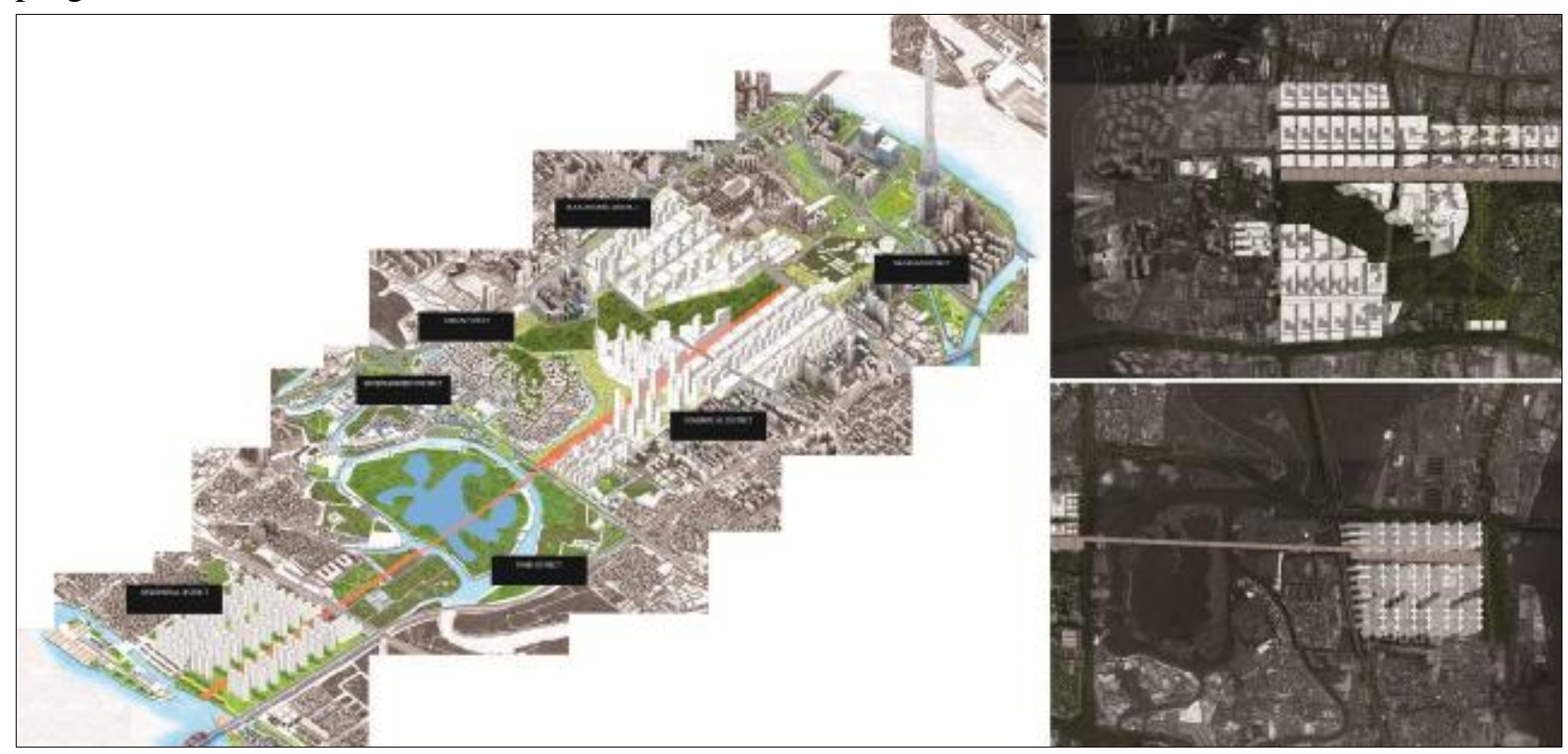

Fig. 9: The Final Combined and Optimized Scenario in the Third Round

\section{Acknowledgements}

This work was financially supported by The National Natural Science Foundation project 2015(51408232), The Central University Basic Science Research Foundation project 2015(D2155280), The National Natural Science Foundation project 2015(51408235).

\section{References}

[1] South China University of Technology + Politecnico Di Torino: Final Report of Watersheds Winter School (2014, Guangzhou).

[2] G. Broadbent: Emerging Concept in Urban Space Design, VRN, 1990.

[3] Ignasib Sola-Morales: Neo-Rationalism and Figuration, London, Academy Group LTD., 1990.

[4] Liu Zhidan, Zhang Chun, song Yan: A Multi-disciplinary, Multi-scale Agenda of Urban Form Studies Toward Sustainable Development: A Literature Review on Urban Form Studies in the USA and China, International City Planning, Vol. 02 (2012), p. 47-53.

[5] Serge Salat: Cities and Forms: on Sustainable Urbanism, China: Hongkong International Culture Publishing Co., Ltd., 2013.1.

[6] John Lund Kriken, Philip Enquist, Richard Rapaport: 《City Building: Nine Planning Principles for the Twenty-First Century》, Princeton Architectural Press, 2013. 